\begin{tabular}{|c|c|c|}
\hline Case Reports in & \multicolumn{2}{|c|}{ Case Rep Gastroenterol 2019;13:468-474 } \\
\hline Gastroenterology & $\begin{array}{l}\text { DOI: } 10.1159 / 000504407 \\
\text { Published online: November 13, } 2019\end{array}$ & $\begin{array}{l}\text { ( } 2019 \text { The Author(s) } \\
\text { Published by S. Karger AG, Basel } \\
\text { www.karger.com/crg }\end{array}$ \\
\hline & $\begin{array}{l}\text { This article is licensed under the } \mathrm{Cr} \\
\text { International License (CC BY-NC) (ht } \\
\text { Usage and distribution for commercial }\end{array}$ & $\begin{array}{l}\text { nons Attribution-NonCommercial } 4.0 \\
\text { ger.com/Services/OpenAccessLicense). } \\
\text { uires written permission. }\end{array}$ \\
\hline
\end{tabular}

\title{
Does the Presence of Giant Pseudopolyps in a Patient with Newly Diagnosed Inflammatory Bowel Disease Increase the Risk of Major Thrombotic Events?
}

\author{
Afshin Amini ${ }^{\mathrm{a}} \quad$ Zahra Vaezi $^{\mathrm{b}} \quad$ Amirsina Talebian $^{\mathrm{a}} \quad$ Elliott Koury $^{\mathrm{a}}$ \\ Elie Chahla ${ }^{a, c}$ \\ aDepartment of Medicine, St. Luke's Hospital, Chesterfield, MO, USA; \\ ${ }^{b}$ Department of Medicine, Zahedan University of Medical Sciences, Zahedan, Iran; \\ 'Division of Gastroenterology and Hepatology, Department of Medicine, \\ St. Luke's Hospital, Chesterfield, MO, USA
}

\section{Keywords}

Giant pseudopolyps · Inflammatory bowel disease · Major thrombotic events

\begin{abstract}
Giant inflammatory polyp and thromboembolism are uncommon complications in inflammatory bowel disease (IBD) patients. Colon mucosal inflammation is possibly the main mechanism of pathogenesis for these two complications. IBD has long been associated with hypercoagulability and thromboembolism. In fact, thromboembolism has been noted in $0.7 \%$ to $7.7 \%$ of IBD patients, with the deep veins of the legs and the pulmonary veins accounting for $90 \%$ of the cases. The proposed mechanism of this hypercoagulability involves the promotion of hemostasis that results from the inflammatory process underlying the IBD, as well as the loss of proteins, including antithrombotic factors, resulting from the inflamed bowel and increased permeability of the colonic mucosa. This process may be exacerbated by the presence of giant inflammatory polyps, which are defined as polyps in the setting of IBD with dimensions greater than $1.5 \mathrm{~cm}$. The presence of these polyps leads to an increase in inflamed colonic surface area, which can accelerate the rate of protein loss, leading to an increased incidence of thrombosis.
\end{abstract}


Here, we report the case of a 21-year-old female with inferior vena cava and left renal vein thromboses secondary to a newly diagnosed IBD and the presence of severe giant inflammatory polyposis. These thromboses were detected incidentally in this patient after 1 week of hospitalization. She had presented with hypoalbuminemia and elevated inflammatory markers, which raised the suspicion for possible giant inflammatory polyposis as a potential risk for her major thromboembolic events. More studies are required to explore this plausible correlation further.

\section{Introduction}

Giant inflammatory polyposis (GIP) and thromboembolism (TE) are uncommon complications of inflammatory bowel disease (IBD). Inflammatory polyps are non-neoplastic mucosal lesions that can develop following repetitive episodes of inflammation, ulceration, and the resulting excessive healing process.

The overall prevalence of these polyps ranges from $4 \%$ to $74 \%$. They are found more often in the colon but have been reported in other parts of the gastrointestinal tract as well. When their size exceeds $1.5 \mathrm{~cm}$, they are classified as giant inflammatory polyps. GIP is a rare complication of IBD and presents most commonly with hematochezia, abdominal pain, weight loss [1], and protein-losing enteropathy [2].

TE is an uncommon but serious extra-intestinal manifestation in IBD patients. This complication is three times more likely in IBD patients as compared to the general population, and the risk increases significantly during disease flares. TE can occur in $0.7 \%$ to $7.7 \%$ of IBD patients, with $90 \%$ of cases occurring in the deep veins of the legs or the pulmonary veins [3]. Despite this, other less frequent sites of thrombosis have also been reported. These include the mesenteric veins, portal vein, and retinal veins. Budd-Chiari syndrome has also been noted, as well as cutaneous gangrene secondary to microvascular thrombosis, and cerebrovascular disease [4].

Herein, we present the unique case of inferior vena cava and left renal vein thromboses secondary to a newly diagnosed IBD with the presence of severe GIP.

\section{Case Report}

A 21-year-old Caucasian female without significant past medical history presented to the emergency department with abdominal pain and intermittent bloody diarrhea for 3 weeks with an average of ten bowel movements per day. She was hemodynamically stable. Physical examination was unremarkable except for diffuse abdomen tenderness with hyperactive bowel sounds. She denied sick contacts, recent travel, alcohol, tobacco, or drug abuse. She did not take any prescribed or over-the-counter medications or supplements. Family history was negative for colon cancer and IBD. She denied any prior abdominal surgeries, colonoscopies, or endoscopies.

Laboratory tests were remarkable for leukocytosis with a white blood cell count of $14,200 / \mu \mathrm{L}$, hemoglobin of $7.8 \mathrm{~g} / \mathrm{dL}$, elevated C-reactive protein at $20.5 \mathrm{mg} / \mathrm{dL}$, erythrocyte sedimentation rate at $36 \mathrm{~mm} / \mathrm{h}$, and albumin level of $2.5 \mathrm{~g} / \mathrm{dL}$. Stool analysis for ova, parasites, culture, and Clostridium difficile toxin assay were all negative. Abdominal CT with intravenous contrast revealed colonic distention, wall thickening, and extensive pneumatosis, highly concerning for severe pancolitis. Complicated IBD was suspected, and the patient was started on 


\section{Case Reports in Gastroenterology}

Case Rep Gastroenterol 2019;13:468-474

DOI: 10.1159/000504407

(c) 2019 www.karger.com/crg

Amini et al: Does the Presence of Giant Pseudopolyps in a Patient with Newly

Diagnosed Inflammatory Bowel Disease Increase the Risk of Major Thrombotic Events?

i.v. steroids. Clinically the patient showed mild and slow improvement. A CT of the abdomen was repeated after 1 week and showed stability and mild improvement of the colonic findings. However, IVC and left renal vein thromboses were incidentally noted (Fig. 1). The patient had not received any venous thromboembolism (VTE) prophylaxis due to her active intermittent lower gastrointestinal bleeding. A CT scan of the chest was obtained and did not show evidence of pulmonary embolism. The patient was started on anticoagulation with close monitoring for any worsening gastrointestinal bleeding. Given the high risk of perforation, slowing of gastrointestinal bleed, and decreased transfusion requirement, colonoscopy was postponed. She eventually responded well to steroid therapy and was discharged home on anticoagulation and slow taper of oral prednisone. An extensive hypercoagulability workup was performed, and it was unrevealing.

Colonoscopy was performed 2 months later and showed multiple tunneled, deep ulcers in the rectosigmoid and sigmoid colon associated with giant pseudopolyps. Colonoscopy was limited to splenic flexure due to the deep ulcerations creating the appearance of a false lumen (Fig. 2a, b). Random biopsies showed evidence of chronic active inflammation with architectural distortion and no evidence of dysplasia (Fig. 2c). Azathioprine and infliximab combination therapy was initiated along with the continuation of the prednisone taper. Prednisone was eventually discontinued in 2 months following the initiation of combination therapy. Follow-up colonoscopy 6 months later demonstrated complete resolution of the inflammation and ulceration with the persistence of smaller pseudopolyps throughout the colon (Fig. 3a). Biopsies confirmed complete resolution of inflammation (Fig. 3b). There was no evidence of small bowel disease, and her clinical picture was more suggestive of ulcerative colitis.

Oral anticoagulation was eventually discontinued due to the complete resolution of the aforementioned thromboses on repeat imaging without any long-term sequelae. The patient achieved clinical, endoscopic, and histologic remission. Her anemia, hypoalbuminemia, and elevated serum markers normalized as well. On subsequent follow-up visits, the patient remained symptom-free and had been compliant with infliximab and azathioprine.

\section{Discussion}

To our knowledge, this is the first reported case of an IBD patient presenting with the combination of GIP and IVC and left renal vein thromboses, both of which are rare complications. GIP was first defined by Hinrichs and Goldman in 1968 as post-inflammatory polyps measuring greater than $15 \mathrm{~mm}$ in height or diameter. The presence of GIP is known to correlate with the severity of IBD [1]. Other terms, such as filiform polyposis, and giant pseudopolyposis, have been used in the literature to describe this type of polyposis. This is an uncommon manifestation and complication of IBD and is seen more frequently in ulcerative colitis [5]. In addition to IBD, GIP can be seen as a result of other inflammatory processes. These include perforation, necrotizing enterocolitis, enema-induced colitis, diverticulitis, stercoral ulcer, colonic tuberculosis, and histiocytosis X [6].

In patients with IBD, long-term inflammation is believed to be a prerequisite for the development of these finger-like polyps. Despite this, GIP can present as the initial manifestation of IBD. There was broad variation in the timing of their first appearance, ranging from months to years [1]. The most common involved site is the transverse colon, followed by the descending and sigmoid colon. The rectum is the least common site of involvement, but when present, the upper third of the rectum is more common [7]. Patients with GIP may have symptoms similar to IBD flares. Symptoms include anemia, weight loss, cramping abdominal pain, 
diarrhea, hematochezia, and colonic obstruction. Most cases remain asymptomatic and go undiagnosed until the patient develops signs and symptoms of obstruction and hematochezia [1]. $15 \%$ of GIP patients are eventually complicated by complete or partial intestinal obstruction [5].

VTE is another known complication of IBD with an incidence that varies between 0.7 and $7 \%$ [3]. Even after correcting for abnormalities of pro-thrombotic factors, the risk of VTE in IBD patients has been estimated to be three times higher than the general population [4]. Another study reported an incidence of VTE complications of 39\% in UC patients. This implies a possible underestimation of thromboembolic episodes in IBD patients [8]. A national multicenter study in Austria evaluated the prevalence and the incidence of VTE in 2,811 IBD patients and noted an overall prevalence of 5.6\%. In this study, approximately $90 \%$ of VTE were deep venous thrombosis and/or pulmonary embolism. Other types of thrombosis included the portal, superior mesenteric, splenic, internal jugular, and cerebral veins [9]. VTE in this setting tends to occur spontaneously, at a younger age, and is more common during periods of active disease [4]. VTE in IBD patients has a higher risk of recurrence, and recurrence rates are linked to the extent of disease activity. The recurrence rate has been reported to be between 10 and $13 \%$ [3].

Acquired risk factors play the most pertinent role in the development of VTE in IBD patients, especially during active disease [10]. It is unclear whether the presence of GIP can itself increase the risk of TE.

It is well documented that the increased intestinal permeability seen in IBD can lead to enteral protein loss and an inflammatory reaction in the bowel wall due to the dysregulated mucosal uptake of luminal bacteria as well as toxic and antigenic substances. This inflammatory reaction, enteral protein loss, and endotoxemia may promote activation of hemostasis and subsequent hypercoagulation [4]. A systemic inflammatory response during active disease can lead to increased cytokines, factor VIII activity, increased fibrinogen levels, thrombin generation, and spontaneous platelet aggregation, all of which can contribute to an increasing thrombotic process [11]. In addition to the relationship between systemic inflammation and VTE, Talbot et al. [3] also described an association between hypoalbuminemia and VTE [12]. Albumin can interact with fibrinogen resulting in impaired fibrinogen activity [13]. Proteinlosing enteropathy can increase the risk of thrombosis by perpetuating the loss of anticlotting factors, namely antithrombin III, protein C, and protein S [14]. The presence of GIP in IBD patients leads to an increase in the colonic mucosal surface area, cell turnover, and permeability. This contributes to protein-losing enteropathy [15] and may represent a link between GIP itself and hypercoagulability.

We have presented the case of a young patient with a life-threatening thrombotic event in the setting of a newly diagnosed severe colonic IBD complicated by GIP. Colonic mucosal inflammation is possibly the primary mechanism contributing to the association between thrombotic events and GIP. Moreover, the presence of these polyps leads to an increase in inflamed colonic surface area, which can accelerate the rate of protein loss, leading to increased incidence of thrombosis, especially during acute flares. GIP itself may be an independent risk factor for severe VTE for this reason. Further studies and research are needed to explore this potential and plausible correlation.

\section{Statement of Ethics}

The authors have no ethical conflicts to disclose. The patient gave permission of the data usage for case presentation. 


\section{Case Reports in Gastroenterology}

\begin{tabular}{l|l}
\hline DOI: 10.1159/000504407 & (c) 2019 The Author(s). Published by S. Karger AG, Basel
\end{tabular} www.karger.com/crg

Amini et al: Does the Presence of Giant Pseudopolyps in a Patient with Newly

Diagnosed Inflammatory Bowel Disease Increase the Risk of Major Thrombotic Events?

\section{Disclosure Statement}

The authors declare that they have no competing interests.

\section{Funding Sources}

No funding was received for this article.

\section{Author Contributions}

Afshin Amini performed the literature review, assisted in the initial manuscript, performed revisions, and is the article guarantor. Zahra Vaezi, Amirsina Talebian, and Elliot Koury performed the literature review and assisted in the initial manuscript. Elie Chahla performed the colonoscopic procedures, performed revisions, and edited the manuscript. All authors read and approved the final manuscript.

\section{References}

1 Politis DS, Katsanos KH, Tsianos EV, Christodoulou DK. Pseudopolyps in inflammatory bowel diseases: have we learned enough? World J Gastroenterol. 2017 Mar;23(9):1541-51.

2 Esaki M, Matsumoto T, Fuyuno Y, Maehata Y, Kochi S, Hirahashi M, et al. Giant inflammatory polyposis of the cecum with repeated intussusception in ulcerative colitis: report of a case. Am J Gastroenterol. 2009 Nov;104(11):2873-4.

3 Talbot RW, Heppell J, Dozois RR, Beart RW Jr. Vascular complications of inflammatory bowel disease. Mayo Clin Proc. 1986 Feb;61(2):140-5.

4 Zezos P, Kouklakis G, Saibil F. Inflammatory bowel disease and thromboembolism. World J Gastroenterol. 2014 Oct;20(38):13863-78.

5 Maggs JR, Browning LC, Warren BF, Travis SP. Obstructing giant post-inflammatory polyposis in ulcerative colitis: case report and review of the literature. J Crohn's Colitis. 2008 Jun;2(2):170-80.

6 Hew JM, Chandie Shaw P, Blickman G. Filiform polyposis: a manifestation of histiocytosis X. RoFo Fortschr Geb Rontgenstr Nuklearmed. 1985 Oct;143(4):474-6.

7 Jones B, Abbruzzese AA. Obstructing giant pseudopolyps in granulomatous colitis. Gastrointest Radiol. 1978 Oct;3(4):437-8.

8 Graef V, et al. Venous Thrombosis Occurring in Nonspecific Ulcerative Colitis. Arch Intern Med. 1966 Mar;117(3):377.

9 Papay P, Miehsler W, Tilg H, Petritsch W, Reinisch W, Mayer A, et al. Clinical presentation of venous thromboembolism in inflammatory bowel disease. J Crohn's Colitis. 2013 Oct;7(9):723-9.

10 Spina L, Saibeni S, Battaglioli T, Peyvandi F, de Franchis R, Vecchi M. Thrombosis in inflammatory bowel diseases: role of inherited thrombophilia. Am J Gastroenterol. 2005 Sep;100(9):2036-41.

11 Esmon CT. The interactions between inflammation and coagulation. Br J Haematol. 2005 Nov;131(4):41730.

12 Olson NC, Cushman M, Lutsey PL, McClure LA, Judd S, Tracy RP, et al. Inflammation markers and incident venous thromboembolism: the REasons for Geographic And Racial Differences in Stroke (REGARDS) cohort [Internet]. J Thromb Haemost. 2014 Dec;12(12):1993-2001.

13 Galanakis DK. Anticoagulant albumin fragments that bind to fibrinogen/fibrin: possible implications. Semin Thromb Hemost. 1992 Jan;18(1):44-52.

14 Kawaguchi Y, Mine T, Kawana I, Umemura S. Protein-losing enteropathy, deep venous thrombosis and pulmonary embolism in a patient with generalized inflammatory polyposis in remission stage of ulcerative colitis. Clin J Gastroenterol. 2009 Jun;2(3):156-60.

15 Anderson R, Kaariainen IT, Hanauer SB. Protein-losing enteropathy and massive pulmonary embolism in a patient with giant inflammatory polyposis and quiescent ulcerative colitis. Am J Med. 1996 Sep;101(3):3235. 


\section{Case Reports in Gastroenterology}

\begin{tabular}{l|l}
\hline Case Rep Gastroenterol 2019;13:468-474 \\
\hline DOI: 10.1159/000504407 & $\begin{array}{l}\text { @ 2019 The Author(s). Published by S. Karger AG, Basel } \\
\text { www.karger.com/crg }\end{array}$ \\
\hline
\end{tabular}

Amini et al:: Does the Presence of Giant Pseudopolyps in a Patient with Newly Diagnosed Inflammatory Bowel Disease Increase the Risk of Major Thrombotic Events?
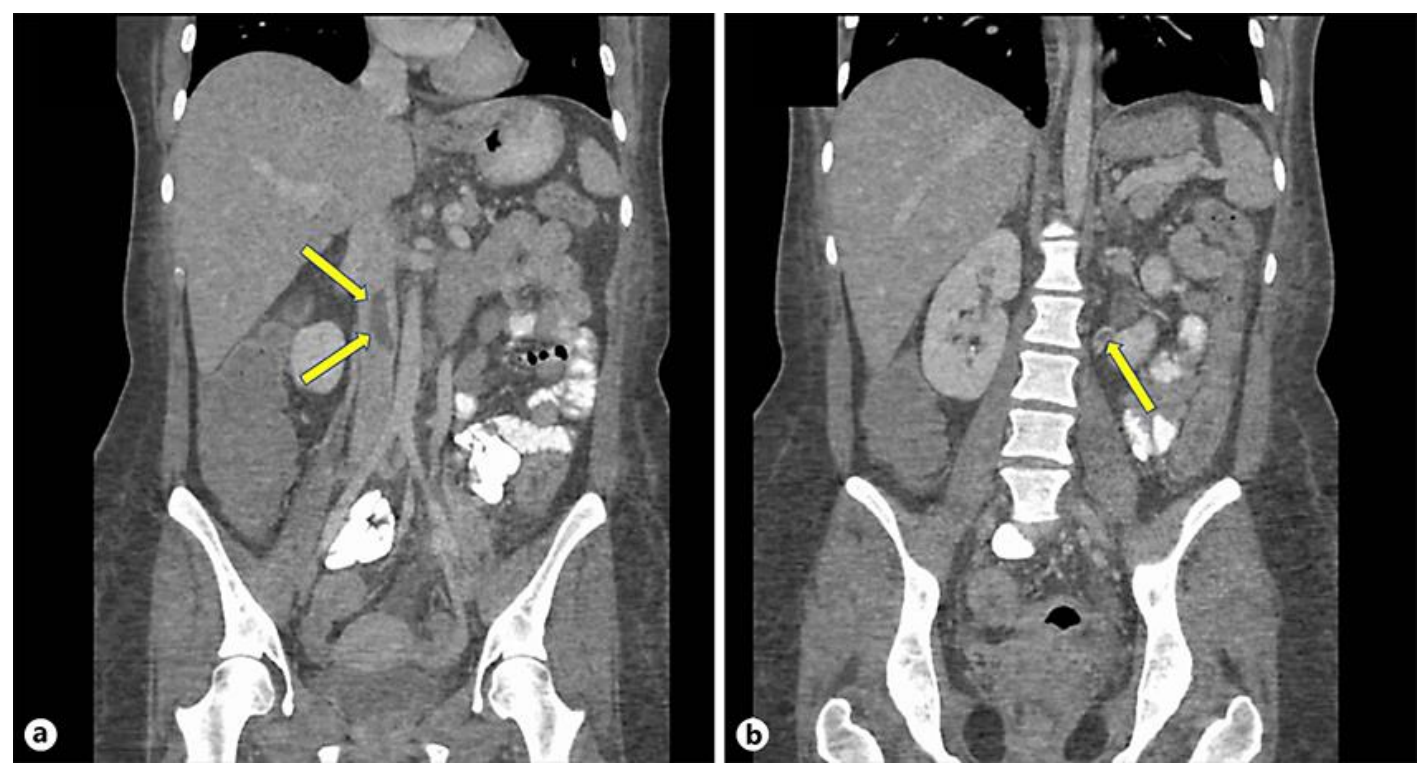

Fig. 1. a Coronal CT of the abdomen demonstrating IVC thrombus extending approximately $4 \mathrm{~cm}$ (arrow). b Left renal vein thrombus (arrow).
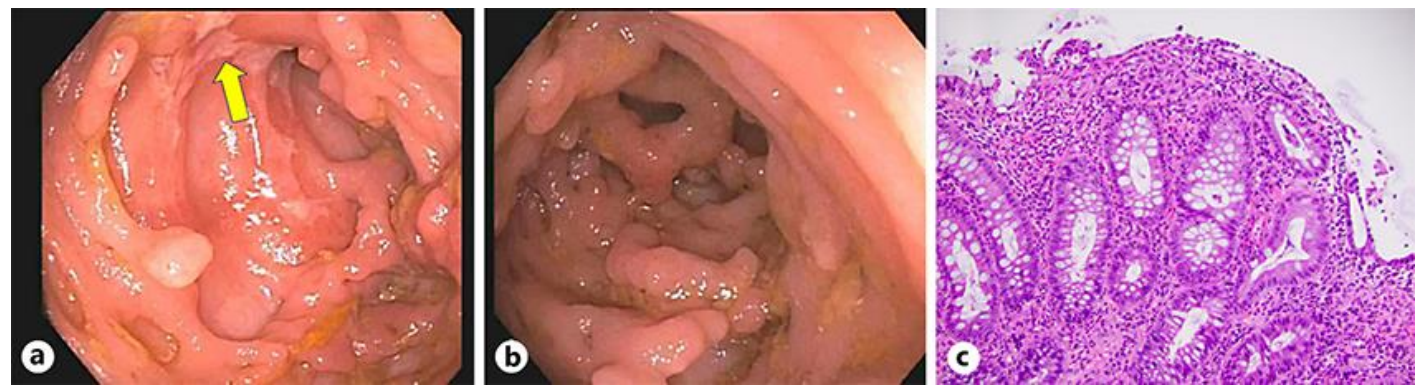

Fig. 2. a Endoscopic view of the sigmoid colon with multiple ulcers with inflammatory changes (arrow). b False lumen creation with surrounding giant pseudopolyps. c Active colitis with cryptitis $(\times 100)$. 


\section{Case Reports in \\ Gastroenterology}

Case Rep Gastroenterol 2019;13:468-474

DOI: 10.1159/000504407

(c) 2019 The Author(s). Published by S. Karger AG, Basel www.karger.com/crg

Amini et al.: Does the Presence of Giant Pseudopolyps in a Patient with Newly

Diagnosed Inflammatory Bowel Disease Increase the Risk of Major Thrombotic Events?
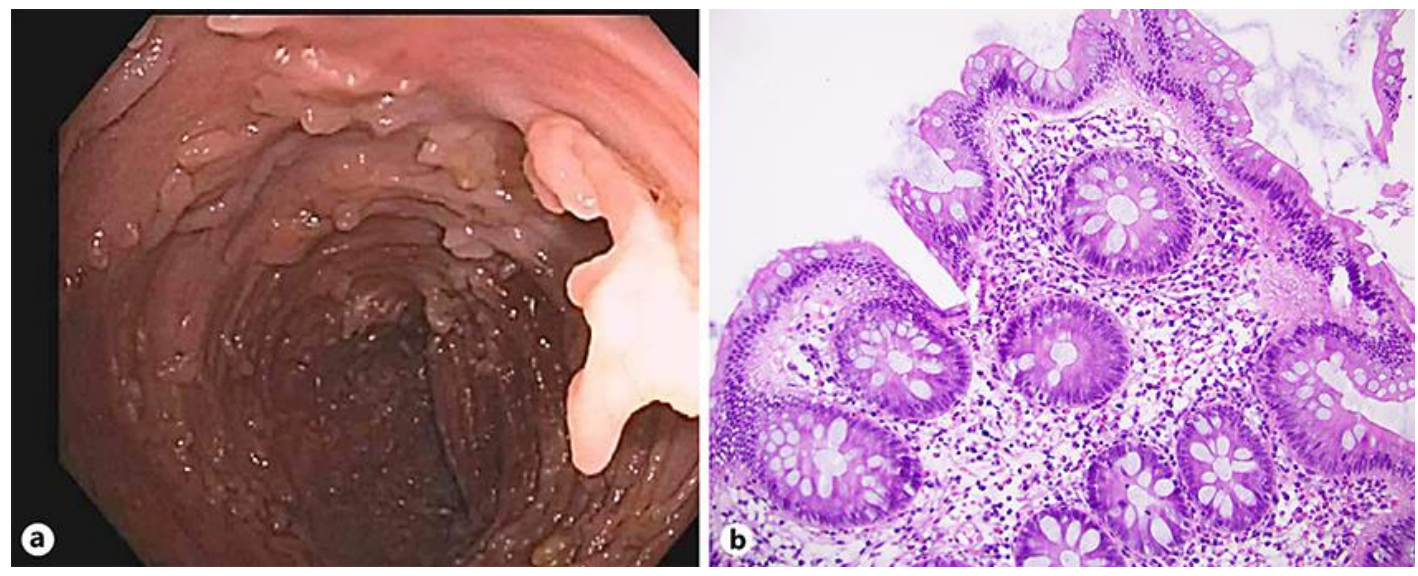

Fig. 3. a Endoscopic view of the sigmoid colon on repeat colonoscopy demonstrating resolution of the acute colitis and residual smaller pseudopolyps. b Chronic mucosa with no histopathologic abnormality. No evidence of active colitis, granulomas, or dysplasia $(\times 400)$. 